\title{
Efeito residual da aplicação de fosfato monoamônio revestido por diferentes polímeros na cultura de milho
}

\author{
Rodolfo de Niro Gazolal, Salatiér Buzetti², Raíssa Pereira Dinalli', \\ Marcelo Carvalho Minhoto Teixeira Filho ${ }^{2 *}$, Thiago de Souza Celestrino ${ }^{1}$
}

\section{RESUMO}

O uso de fertilizantes fosfatados, revestidos por polímeros, pode permitir a redução de perdas que ocorrem no processo de fixação do fósforo no solo, disponibilizando, assim, esse elemento por um maior período de tempo. Objetivou-se, com este trabalho, estudar o efeito residual de doses de fósforo e de formas de fosfato monoamônio revestido por polímeros, no que se refere aos componentes de produção e produtividade do milho, em primeira e segunda safra. O experimento foi conduzido em campo, num Latossolo Vermelho distrófico, textura argilosa. O delineamento estatístico foi o de blocos ao acaso, dispostos em esquema fatorial 4 x 4, sendo: quatro doses de $\mathrm{P}_{2} \mathrm{O}_{5}: 0,50,100$ e $150 \mathrm{~kg} \mathrm{ha}^{-1}$, aplicadas na semeadura, em quatro formas: fosfato monoamônio (MAP) convencional e MAP revestido por três diferentes polímeros, com quatro repetições. Os tratamentos foram aplicados no milho safra e safrinha, e, posteriormente, avaliou-se o efeito residual desses tratamentos nos cultivos sucessores do milho, que foram semeados nas mesmas linhas de semeadura dos cultivos anteriores. O teor de fósforo residual no solo aumentou linearmente até a dose de $150 \mathrm{~kg} \mathrm{ha}^{-1} \mathrm{de}_{2} \mathrm{O}_{5}$. As formas de MAP revestido por polímeros apresentaram o mesmo efeito residual que MAP convencional, pois proporcionaram resultados semelhantes para as avaliações do milho irrigado. O incremento das doses de fósforo na cultura anterior proporcionou efeito residual, alterando o teor de $\mathrm{P}$ foliar e a altura de plantas do milho safrinha irrigado e aumentando a produtividade de grãos de milho, na primeira safra, até a dose de $118 \mathrm{~kg} \mathrm{ha}^{-1}$ de $\mathrm{P}_{2} \mathrm{O}_{5}$, independentemente da forma de MAP.

Palavras-chave: Zea mays L., adubação fosfatada, fertilizante revestido, liberação gradual, eficiência de fósforo.

\begin{abstract}
Residual effect of monoammonium phosphate coated with different polymers on maize

The use of phosphate fertilizers coated with polymers can reduce losses by phosphorus fixation in the soil, providing the element for a longer period of time. The objective of this study was to evaluate the residual effect of phosphorus rates and forms of monoammonium phosphate coated with different polymers on production components and grain yield of maize in the first and second harvest. The experiment was conducted in Selvíria - MS, in a loamy Oxisol. A randomized block design in a 4 x 4 factorial scheme with four repetitions was used in the experiment: four $\mathrm{P}_{2} \mathrm{O}_{5}$ rates $\left(0,50,100\right.$ and $\left.150 \mathrm{~kg} \mathrm{ha}^{-1}\right)$ applied at sowing, in four forms: conventional monoammonium phosphate and monoammonium phosphate coated with three different polymers. To evaluate the residual effect of these treatments on the maize successor crop, the new crop was sown in the same line of the previous crop. The residual level of phosphorus in the soil increased linearly up to $150 \mathrm{~kg} \mathrm{ha}^{-1} \mathrm{P}_{2} \mathrm{O}_{5}$. The MAP coated with polymers showed the same residual effect of
\end{abstract}

Recebido para publicação em 06/06/2012 e aprovado em 25/06/2013.

${ }^{1}$ Engenheiros-Agrônomos. Departamento de Fitossanidade, Engenharia Rural e Solos, Universidade do Estado de São Paulo, Campus de Ilha Solteira, Avenida Brasil, 56, Centro, 15385-000, Ilha Solteira, São Paulo, Brasil. rodolfodng@hotmail.com; raissa_dinalli@hotmail.com; thiagomel_2@hotmail.com

${ }^{2}$ Engenheiros-Agrônomos, Doutores. Departamento de Fitossanidade, Engenharia Rural e Solos, Universidade do Estado de São Paulo, Campus de Ilha Solteira, Rua Monção, 226, Zona Norte, 15385-000, Ilha Solteira, São Paulo, Brasil. sbuzetti@agr.feis.unesp.br; mcmtf@yahoo.com.br (*autor para correspondência). 
the conventional MAP, because they provided similar results to the evaluations of the irrigated maize. The increment of phosphorus rates in the previous crop provided residual effect, changing the $\mathrm{P}$ leaf content and plant height of irrigated maize in the second harvest and increasing the grain yield in the first harvest up to the rate of $118 \mathrm{~kg} \mathrm{ha}^{-1} \mathrm{P}_{2} \mathrm{O}_{5}$, regardless of the MAP form.

Key words: Zea mays L., phosphorus fertilization, coated fertilizer, gradual liberation, phosphorus efficiency.

\section{INTRODUÇÃO}

A produção nacional de milho, na safra 2011/12, foi de 72,8 milhões de toneladas, sendo que a segunda safra contribuiu com 53\% desse total, 38,5 milhões de toneladas (Conab, 2012). A produtividade média da primeira safra 2010/11 foi de $4.538 \mathrm{~kg} \mathrm{ha}^{-1}$ e, a da segunda safra, de $3.645 \mathrm{~kg} \mathrm{ha}^{-1}$, sendo essas inferiores às médias de outros países, como a China, com $5.560 \mathrm{~kg} \mathrm{ha}^{1}$, e os Estados Unidos, com $9.660 \mathrm{~kg} \mathrm{ha}^{-1}$ (Agrianual, 2011).

Dentre os fatores que afetam a produtividade da cultura, no Brasil, está o baixo aproveitamento dos fertilizantes fosfatados e, consequentemente, a má nutrição das plantas (Silva et al., 2012). O fósforo (P) constitui o nutriente mais limitante para as culturas agrícolas, especialmente em solos tropicais, que apresentam, em geral, baixo teor de P disponível e predominância de acidez (Araújo, 2011). Segundo Sousa \& Lobato (2004), os teores de $P$ nos solos da região do Cerrado são muito baixos. Essa característica, associada à alta capacidade que esses solos têm para reter o P na fase sólida são a principal limitação para o desenvolvimento de qualquer atividade agrícola rentável, sem a aplicação de adubos fosfatados. Portanto, a adubação fosfatada é um investimento inicial alto, pelas grandes quantidades utilizadas, por causa do baixo teor natural de fósforo e de sua alta adsorção pelos solos (Sousa \& Lobato, 2004).

Uma alternativa para aumentar a eficiência das adubações é o seu parcelamento. Outra seria usar fontes de fertilizantes de liberação mais gradual ou controlada dos nutrientes. Estes fertilizantes são chamados de fertilizantes de liberação lenta (slow release), como os fertilizantes polimerizados (Machado \& Souza, 2012). Uma das formas de se reduzir as perdas de P é a liberação gradual dos nutrientes contidos nos fertilizantes, daí a importância dos polímeros ou adubos revestidos. Segundo Figueiredo et al. (2012), o uso de fósforo polimerizado vem sendo apresentado como uma nova opção para a redução da adsorção do $\mathrm{P}$ pelos coloides do solo. Por se tratar, porém, de um produto ainda novo, em termos de pesquisas, pouco se sabe sobre seu comportamento em solos ácidos. Valderrama et al. (2009) relataram que o uso de fontes fosfatadas de liberação gradual pode trazer diminuição do custo de produção e menores impactos ambientais, reduzindo as perdas por fixação de $P$.

O que se busca, com a nova tecnologia de encapsulamento de fertilizantes, é que se forme uma camada protetora contra os agentes causadores da perda de nutrientes e que essa proteção não interfira na disponibilização do nutriente à planta. Outro aspecto buscado é um comportamento diferente das fontes solúveis convencionais, ou seja, que o revestimento provoque uma disponibilização gradativa e não uma liberação total (Silva et al., 2012). Em relação ao modo de liberação do nutriente, isto envolve a difusão do fertilizante solúvel do interior do grânulo para o solo. A água penetra por microporos através do material de cobertura, aumenta a pressão osmótica no interior do grânulo, a qual provoca o esticamento da membrana de cobertura e o aumento do tamanho dos poros, facilitando a difusão do fertilizante para o solo (Cantarella, 2007).

A liberação gradual, promovida pelo revestimento do fertilizante fosfatado, como o MAP (fonte solúvel), teoricamente faz com que o contato do fósforo com os óxidos de Fe e Al e a argila seja reduzido, reduzindo assim drasticamente a formação de compostos estáveis, o que diminui a disponibilidade do nutriente no solo. Portanto, a utilização de fertilizantes revestidos por polímeros pode proporcionar menores perdas e maior disponibilidade de P no solo, ao longo do tempo, passível de absorção pelas plantas. Considerando-se o restante do $\mathrm{P}$ que permanece no solo, em formas de maior ou menor disponibilidade para as plantas, o efeito residual passa a ser um componente muito importante na avaliação agronômica e econômica de práticas de adubação fosfatada (Resende et al., 2006). Ainda mais, em algumas regiões brasileiras produtoras de grãos, alguns solos apresentam teores de $\mathrm{P}$ médios e, às vezes, até altos. Portanto, já existem agricultores que estão aproveitando o efeito residual de fertilizantes fosfatados para diminuir o custo de produção.

Várias pesquisas vêm sendo realizadas, para observar a eficiência do uso de fertilizantes de liberação lenta; são raros, porém, os estudos que avaliaram o efeito residual desses fertilizantes na cultura sucessora. Sendo assim, 
este trabalho teve como objetivo avaliar o efeito residual de doses de $\mathrm{P}$ e de formas de fosfato monoamônio, convencional e revestido por diferentes polímeros, nos componentes de produção e na produtividade da cultura de milho, em dois ciclos sucessivos.

\section{MATERIAL E MÉTODOS}

Os experimentos foram conduzidos na safra 2010/2011 e na safrinha 2011, na Fazenda de Ensino, Pesquisa e Extensão (FEPE), em Selvíria, Mato Grosso do Sul, da Faculdade de Engenharia de Ilha Solteira (FEIS/UNESP), situada aproximadamente nas coordenadas geográficas $51^{\circ} 22^{\prime}$ $\mathrm{W}$ e $20^{\circ} 22^{\prime} \mathrm{S}$, com altitude local de 335 metros, em área antes cultivada com milho. O solo da área experimental é classificado como Latossolo Vermelho distrófico, textura argilosa, segundo a nova denominação do Sistema Brasileiro de Classificação de Solos (Embrapa, 2006), com valores de granulometria de 420, 50 e $530 \mathrm{~g} \mathrm{~kg}^{-1}$, de areia, silte e argila, respectivamente. As características químicas do solo foram determinadas em setembro de 2009, segundo metodologia proposta por Raij et al. (2001), com os seguintes atributos, na camada $0,0-0,20 \mathrm{~m}: \mathrm{P}($ resina $)=22 \mathrm{mg}$ $\mathrm{dm}^{-3} ; \mathrm{MO}=32 \mathrm{~g} \mathrm{dm}^{-3} ; \mathrm{pH}\left(\mathrm{CaCl}_{2}\right)=5,4 ; \mathrm{K}, \mathrm{Ca}, \mathrm{Mg}, \mathrm{H}+\mathrm{Al}=$ 3,$2 ; 30,0 ; 16,0$ e $32,8 \mathrm{mmol}_{\mathrm{c}} \mathrm{dm}^{-3}$, respectivamente e $60 \%$ de saturação por bases.

A classificação climática da região, de acordo com Köppen, é Aw, definido como tropical úmido, com estação chuvosa no verão e, seca, no inverno. A temperatura média anual é de $23,5^{\circ} \mathrm{C}$, a precipitação pluvial média anual é de $1.370 \mathrm{~mm}$ e, a umidade relativa do ar média anual, entre 70 e $80 \%$. Os dados climáticos registrados durante a condução do experimento constam na Figura 1, onde se encontram os dados de precipitação pluvial, temperatura média e umidade relativa do ar durante o desenvolvimento do experimento, dos anos agrícolas 2010/2011, registrados na Estação Meteorológica da Fazenda Experi-
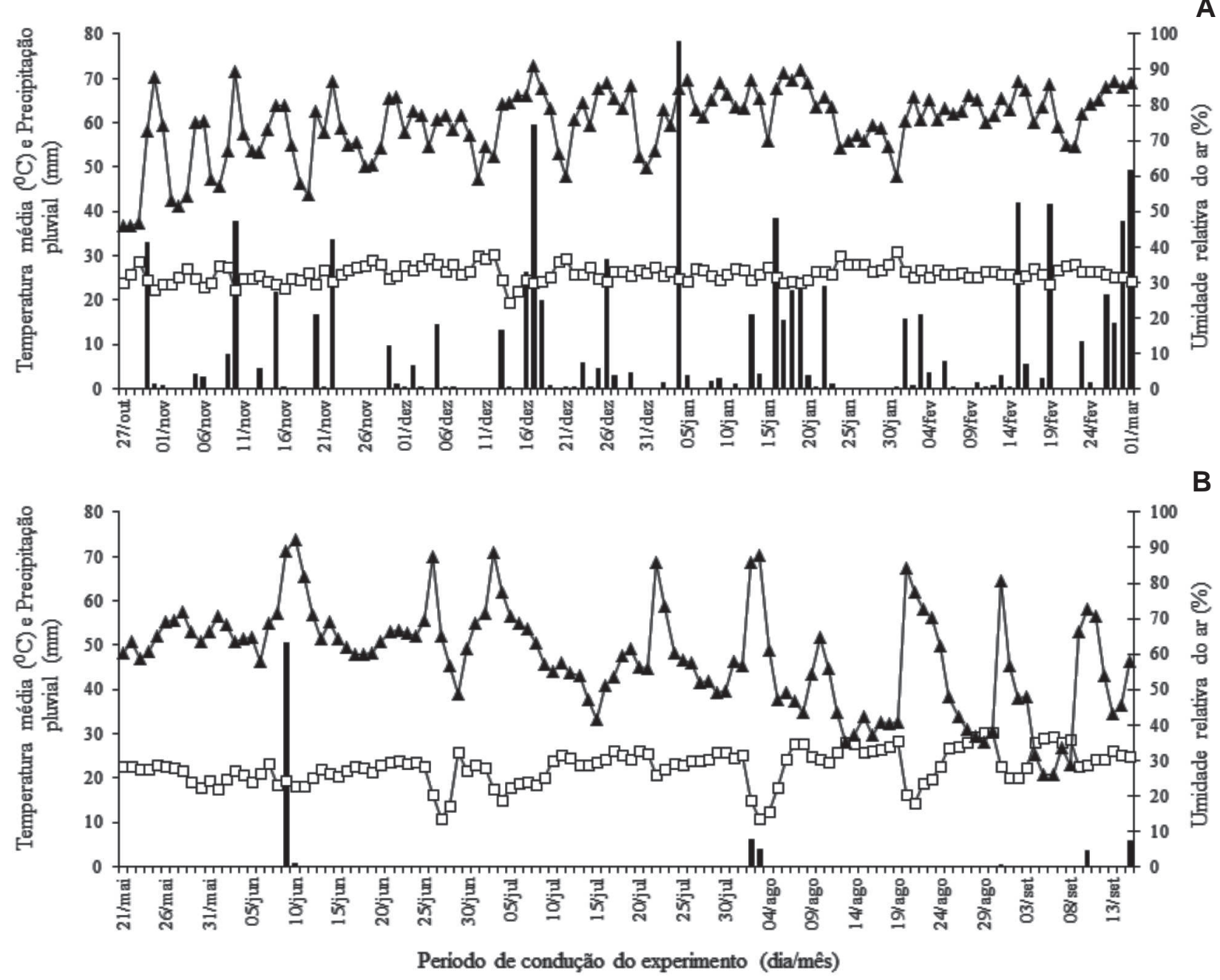

\begin{tabular}{|lll}
\hline$\square$ Precipitação & - -Temp. média & ^UR \\
\hline
\end{tabular}

Figura 1. Precipitação pluvial $(\mathrm{mm})$, temperatura média $\left({ }^{\circ} \mathrm{C}\right)$ e umidade relativa do ar $(\%)$, em Selvíria, Mato Grosso do Sul, durante a condução do experimento com a cultura do milho na safra de verão 2010/2011 (A) e com a cultura do milho safrinha em 2011 (B). 
mental da UNESP. O fornecimento de água foi efetuado de três em três dias, ou quando necessário, com uma lâmina de água de, aproximadamente, $14 \mathrm{~mm}$, com sistema de irrigação por aspersão.

A semeadura do milho foi realizada, mecanicamente, no dia 27 de outubro de 2010, para primeira safra (2010/ 11), e em 21 de maio de 2011, para segunda safra (2011), em área previamente dessecada com aplicação de glifosato (1.800 g do i.a. ha $\left.{ }^{-1}\right)$ e 2,4-D (670 g do i.a. ha-1) em área total. Utilizou-se o híbrido simples Biogene 7049, visando a uma população de 60 mil plantas ha-1, com espaçamento entre linhas de $0,90 \mathrm{~m}$ e densidade de semeadura de 5,4 sementes por metro.

O delineamento experimental foi o de blocos ao acaso, com 16 tratamentos e quatro repetições. Os tratamentos constaram de quatro doses de $\mathrm{P}_{2} \mathrm{O}_{5}: 0,50,100$ e $150 \mathrm{~kg} \mathrm{ha}^{-1}$, aplicadas no cultivo de milho no ano agrícola 2009/2010, sendo essa quantia aplicada na semeadura da primeira safra (2009/10) e da segunda safra (2010), e de quatro formas de fosfato monoamônio: convencional e fosfato monoamônio revestido por três polímeros. Cada parcela constou de seis linhas de $5 \mathrm{~m}$. Para avaliar o efeito residual desta adubação fosfatada, no cultivo sucessor de milho, na primeira e segunda safra, foi realizada a semeadura exatamente na linha de semeadura da cultura antecessora.

Os três diferentes polímeros de revestimento do fosfato monoamônio utilizados foram: 0041, 0056 e 0228 . O processo para obtenção de grânulo de fósforo com liberação gradativa (L.G.P.) consiste no recobrimento do grânulo do fosfato monoamônio por camadas de polímeros, definidos como lgp101, lgps02, lgps03 e lgp104, sendo que, para isso se faz a aplicação individual de cada um dos polímeros citados, em operações de nebulização sucessivas e acumulativas, ou seja, cada nova nebulização de polímero sobrepõe-se à camada anterior de recobrimento, até que se chegue ao produto desejado, o grânulo de fósforo revestido.

A adubação de semeadura para $\mathrm{N}$ e $\mathrm{K}$, na primeira (2010/11) e segunda safra (2011), foi realizada com base na análise do solo e na tabela de recomendação de adubação para a cultura do milho irrigado, para o Estado de São Paulo, conforme descrito em Cantarella et al. (1997), sendo aplicados $30 \mathrm{~kg} \mathrm{ha}^{-1}$ de $\mathrm{N}$ e $40 \mathrm{~kg} \mathrm{ha}^{-1}$ de $\mathrm{K}_{2} \mathrm{O}$, utilizando-se, como fontes, a ureia e o cloreto de potássio, respectivamente. A adubação fosfatada não foi realizada na primeira (2010/11) e segunda safra (2011), conforme descrito anteriormente. No caso da adubação nitrogenada, nas semeaduras da primeira (2009/10) e segunda safra (2010), foi descontada a quantidade de N presente na fonte de fosfato monoamônio. A adubação nitrogenada de cobertura ( $80 \mathrm{~kg} \mathrm{ha}^{-1}$ de $\mathrm{N}$, usando-se a ureia como fonte) foi realizada quando as plantas apresentaram seis folhas totalmente desdobradas, para todos os tratamentos, posicionando-se o adubo na entrelinha, a uma distância de 0,20 $\mathrm{m}$ da linha da cultura. Após a adubação, foi realizada a irrigação das parcelas, para minimizar as perdas de nitrogênio por volatilização da amônia, que ocorre por causa da hidrólise da ureia.

O manejo de plantas daninhas foi efetuado com a aplicação da mistura de herbicidas tembotriona ( $84 \mathrm{~g}$ do i.a. ha $^{-1}$ ) e atrazina ( $1.000 \mathrm{~g}$ do i.a. ha $\left.{ }^{-1}\right)$, mais a adição de um adjuvante na calda herbicida, o óleo vegetal (720 g do i.a. $\mathrm{ha}^{-1}$ ), em pós-emergência. Para o controle das lagartasdo-cartucho (Spodoptera frugiperda), foram utilizados o metomil (215 g do i.a. ha $\left.{ }^{-1}\right)$ e triflumurom ( $24 \mathrm{~g}$ do i.a. ha-1). A colheita do milho foi realizada individual e manualmente, por unidade experimental, colhendo-se as quatro linhas centrais, de dois metros cada, no dia 01 de março de 2011 (primeira safra) e em 15 de setembro de 2011 (segunda safra). O material foi submetido à secagem, a pleno sol, e posterior trilhagem.

Foram realizadas as seguintes avaliações: a) teor de fósforo foliar, coletando-se o terço médio de 20 folhas da inserção da espiga principal, no florescimento feminino das plantas, de cada parcela, segundo a metodologia descrita por Cantarella et al. (1997); b) teor de clorofila foliar, determinado indiretamente na folha da inserção da espiga, de cinco plantas de milho por parcela, quando as plantas estavam no estádio de florescimento da cultura, por meio de leituras ICF, com auxílio de um clorofilômetro digital CFL 1030 Falker. Uma semana antes da colheita da cultura foram avaliados: c) diâmetro do segundo internódio do colmo; d) altura de inserção da primeira espiga; e) altura de plantas na maturação, definida como sendo a distância (m) do nível do solo ao ápice do pendão. Da área útil de cada parcela, foram coletadas cinco espigas, ao acaso, para contagem manual de: f) número de grãos por fileira; g) número fileiras por espiga; $h$ ) número de grãos por espiga; i) massa de 100 grãos, determinada em balança de precisão de $0,01 \mathrm{~g}$, com o teor de água dos grãos corrigidos para $13 \%$ (base úmida); j) produtividade de grãos, determinada pela coleta das plantas; e k) amostragem do solo na linha de semeadura nas profundidades de 0-20 e 20-40 $\mathrm{cm}$, realizada após a colheita do milho safrinha (2011) para determinação do teor de P residual.

Os dados foram submetidos à análise de variância (teste F) e, as médias, comparadas pelo teste de Tukey, a 5\% de probabilidade; para formas de fosfato monoamônio e para doses de fósforo, foi utilizada análise de regressão. Para análise estatística, foi utilizado o programa SISVAR (Ferreira, 2008).

\section{RESULTADOS E DISCUSSÃO}

As formas de fosfato monoamônio (MAP) não diferiram, significativamente, para teor foliar de P, índice de 
clorofila foliar, diâmetro do segundo internódio do colmo, altura de inserção da primeira espiga e altura de plantas de milho, nos cultivos de safra e de safrinha (Tabelas 1 e 2), mostrando, assim, que o MAP revestido não se sobressaiu em relação ao MAP convencional.Também não houve diferença significativa entre as formas de MAP revestido e o MAP convencional para os componentes de produção e produtividade de grãos de milho, nos dois cultivos (Tabelas 3 e 4). Portanto, não houve a liberação gradual de fósforo dos grânulos revestidos com os três diferentes polímeros de revestimento do MAP (P 0041, P 0056 e P 0228). A não eficácia destes polímeros pode estar relacionada com a sua rápida degradação, favorecida pelas condições climáticas da região, que apresenta elevadas temperaturas (Figura 1) e solos muito argilosos, que retêm umidade, consequentemente não disponibilizando esse elemento por um maior período de tempo.

Outra explicação, relatada por Figueiredo et al. (2012), seria que a elevação da saturação de bases para altos valores, como $60 \%$ (valor este semelhante ao encontrado nesta pesquisa), diminui a eficiência do polímero do MAP revestido, provavelmente pela saturação dos sítios de troca desses polímeros com cátions como Ca e $\mathrm{Mg}$, facilitando, assim, a precipitação de fósforo solúvel pelo excesso desses cátions no solo. Em solo com saturação por bases de 60\%, Valderrama et al. (2009) não constataram diferenças entre superfosfato simples convencional e polimerizado, na cultura do feijão. Por outro lado, Jagadeeswaran et al. (2005) verificaram que, independentemente do $\mathrm{pH}$ do solo, o adubo revestido com polímero promoveu maior

Tabela 1. Teores foliares de fósforo (PF), índice de clorofila foliar (ICF), diâmetro do segundo internódio do colmo (DSI), altura de inserção da primeira espiga (IPE) e altura de plantas (AP) de milho na primeira safra (2010/11) em função dos tratamentos

\begin{tabular}{|c|c|c|c|c|c|c|}
\hline Tratamentos & & $\begin{array}{c}\mathbf{P F} \\
\left(\mathrm{g} \mathrm{kg}^{-1} \text { de MS }\right)\end{array}$ & ICF & $\begin{array}{c}\text { DSI } \\
(\mathrm{mm})\end{array}$ & $\begin{array}{l}\text { IPE } \\
(\mathrm{m})\end{array}$ & $\begin{array}{l}\text { AP } \\
(\mathrm{m})\end{array}$ \\
\hline \multirow[t]{4}{*}{ Formas de MAP } & C 0052 & $2,8 \mathrm{a}$ & $58,83 \mathrm{a}$ & $21,29 \mathrm{a}$ & $1,49 \mathrm{a}$ & $2,65 a$ \\
\hline & P 0041 & $2,9 \mathrm{a}$ & 59,48 a & $21,07 \mathrm{a}$ & $1,45 \mathrm{a}$ & $2,62 \mathrm{a}$ \\
\hline & P 0056 & $2,9 \mathrm{a}$ & $58,21 \mathrm{a}$ & $21,40 \mathrm{a}$ & $1,50 \mathrm{a}$ & $2,63 a$ \\
\hline & P 0228 & $2,9 \mathrm{a}$ & $59,32 \mathrm{a}$ & $20,55 \mathrm{a}$ & $1,48 \mathrm{a}$ & $2,64 \mathrm{a}$ \\
\hline D.M.S. (5\%) & & 0,2 & 4,35 & 1,81 & 0,06 & 0,06 \\
\hline \multirow{4}{*}{$\begin{array}{l}\text { Dose de } \mathrm{P}_{2} \mathrm{O}_{5} \\
\left(\mathrm{~kg} \mathrm{ha}^{-1}\right)\end{array}$} & 0 & 2,9 & 59,75 & 20,11 & 1,52 & 2,68 \\
\hline & 50 & 2,9 & 58,05 & 21,21 & 1,47 & 2,63 \\
\hline & 100 & 2,8 & 58,43 & 21,91 & 1,46 & 2,62 \\
\hline & 150 & 2,9 & 59,61 & 21,06 & 1,47 & 2,61 \\
\hline C.V. $(\%)$ & & 5,32 & 7,81 & 9,11 & 4,12 & 2,61 \\
\hline Média Geral & & 2,9 & 58,96 & 21,07 & 1,48 & 2,64 \\
\hline
\end{tabular}

Médias seguidas de mesma letra na coluna não diferem pelo teste de Tukey, a $5 \%$ de probabilidade. $\mathrm{C}=$ MAP convencional , $\mathrm{P}=\mathrm{MAP}$ revestido por polímeros.

Tabela 2. Teores foliares de fósforo (PF), o índice de clorofila foliar (ICF), diâmetro do segundo internódio do colmo (DSI), altura de inserção da primeira espiga (IPE) e altura de plantas (AP) de milho safrinha (em 2011) em função dos tratamentos

\begin{tabular}{|c|c|c|c|c|c|c|}
\hline Tratamentos & & $\begin{array}{c}\mathbf{P F} \\
\left(\mathrm{g} \mathrm{kg}^{-1} \text { de MS }\right)\end{array}$ & ICF & $\begin{array}{l}\text { DSI } \\
(\mathrm{mm})\end{array}$ & $\begin{array}{l}\text { IPE } \\
(\mathrm{m})\end{array}$ & $\begin{array}{l}\mathbf{A P} \\
(\mathrm{m})\end{array}$ \\
\hline \multirow[t]{4}{*}{ Formas de MAP } & $\mathrm{C} 0052$ & $2,4 \mathrm{a}$ & $52,90 \mathrm{a}$ & $18,84 \mathrm{a}$ & $1,14 \mathrm{a}$ & $2,05 \mathrm{a}$ \\
\hline & P 0041 & $2,5 \mathrm{a}$ & $52,50 \mathrm{a}$ & $20,54 \mathrm{a}$ & $1,10 \mathrm{a}$ & $2,05 \mathrm{a}$ \\
\hline & P 0056 & $2,5 \mathrm{a}$ & $52,98 \mathrm{a}$ & $19,91 \mathrm{a}$ & $1,15 \mathrm{a}$ & $2,09 \mathrm{a}$ \\
\hline & P 0228 & $2,5 \mathrm{a}$ & $53,00 \mathrm{a}$ & $20,06 \mathrm{a}$ & $1,13 \mathrm{a}$ & $2,08 \mathrm{a}$ \\
\hline D.M.S. (5\%) & & 0,2 & 5,03 & 1,71 & 0,06 & 0,05 \\
\hline \multirow{4}{*}{$\begin{array}{l}\text { Dose de } \mathrm{P}_{2} \mathrm{O}_{5} \\
\left(\mathrm{~kg} \mathrm{ha}^{-1}\right)\end{array}$} & 0 & $2,3^{(1)}$ & 51,65 & 19,42 & 1,14 & $2,05^{(2)}$ \\
\hline & 50 & 2,6 & 53,47 & 19,58 & 1,10 & 2,03 \\
\hline & 100 & 2,5 & 52,36 & 20,48 & 1,15 & 2,09 \\
\hline & 150 & 2,6 & 53,89 & 19,87 & 1,16 & 2,10 \\
\hline C.V. $(\%)$ & & 5,53 & 10,09 & 9,13 & 5,56 & 2,69 \\
\hline Média Geral & & 2,5 & 52,84 & 19,84 & 1,14 & 2,07 \\
\hline
\end{tabular}

Rev. Ceres, Viçosa, v. 60, n.6, p. 876-884, nov/dez, 2013 
eficiência de utilização do fósforo pela cultura do açafrão, quando comparado com o MAP convencional.

Na mesma região de estudo, Valderrama et al. (2011) observaram que o superfosfato triplo revestido não diferiu do superfosfato triplo convencional, para os componentes de produção e produtividade de grãos de milho irrigado, sob plantio direto num solo com teor de fósforo médio ( $\left.31 \mathrm{mg} \mathrm{dm}^{-3}\right)$. Entretanto, Figueiredo et al. (2012) constataram que o MAP revestido com polímero promoveu melhor desempenho do milho, quanto à produtividade, produção de massa da matéria seca total e altura de planta, em comparação com o MAP convencional, nos níveis de saturação por bases de 40 e 50\%. Por sua vez, Guareschi et al. (2011) constataram que a aplicação a lanço de $\mathrm{KCl}$ e superfosfato triplo, revestidos por polímeros, 15 dias antes da semeadura, proporcio- nou maior produção de matéria seca, de número de vagens por planta e maior produtividade de grãos de soja, em relação a esses fertilizantes nas formas convencionais. Porém, esses autores verificaram que, quando aplicados na semeadura, estes fertilizantes proporcionaram a mesma produtividade de grãos e de matéria seca de soja, em Rio Verde, Goiás.

A eficácia dos fertilizantes revestidos depende da solubilidade do polímero que reveste o grânulo, em relação à água. Isto irá regular o processo de fornecimento dos nutrientes. Essas taxas de liberação e de dissolução de fertilizantes solúveis em água dependem dos materiais de revestimento (Jarosiewicz \& Tomaszewska, 2003). Ainda, segundo estes autores, a liberação do nutriente irá depender da temperatura e da umidade do solo. Além disso, a espessura e a natureza química da resina de recobrimento,

Tabela 3. Números de grãos por fileira (NGF), de fileiras por espiga (NFE), de grãos por espiga (NGE), massa de 100 grãos (MCG) e produtividade de grãos (PG) de milho na primeira safra (2010/11) em função dos tratamentos

\begin{tabular}{|c|c|c|c|c|c|c|}
\hline Tratamentos & & NGF & NFE & NGE & $\begin{array}{c}\text { MCG } \\
(\mathrm{g})\end{array}$ & $\begin{array}{c}\text { PG } \\
\left(\mathrm{kg} \mathrm{ha}^{-1}\right)\end{array}$ \\
\hline \multirow[t]{4}{*}{ Formas de MAP } & C 0052 & $38,17 \mathrm{a}$ & $15,54 \mathrm{a}$ & $592,89 \mathrm{a}$ & $31,84 \mathrm{a}$ & $8651 \mathrm{a}$ \\
\hline & P 0041 & $38,23 \mathrm{a}$ & $15,42 \mathrm{a}$ & $588,58 \mathrm{a}$ & $29,78 \mathrm{a}$ & $8591 \mathrm{a}$ \\
\hline & P 0056 & 38,19 a & $16,17 \mathrm{a}$ & $617,11 \mathrm{a}$ & $31,71 \mathrm{a}$ & $9101 \mathrm{a}$ \\
\hline & $\mathrm{P} 0228$ & $38,10 \mathrm{a}$ & $15,46 \mathrm{a}$ & $589,19 \mathrm{a}$ & $31,33 \mathrm{a}$ & $9279 \mathrm{a}$ \\
\hline D.M.S. (5\%) & & 2,17 & 0,92 & 45,13 & 2,52 & 870 \\
\hline \multirow{4}{*}{$\begin{array}{l}\text { Dose de } \mathrm{P}_{2} \mathrm{O}_{5} \\
\left(\mathrm{~kg} \mathrm{ha}^{-1}\right)\end{array}$} & 0 & 37,75 & 15,67 & 591,00 & 29,73 & $7617^{(1)}$ \\
\hline & 50 & 38,33 & 15,37 & 589,30 & 32,44 & 9120 \\
\hline & 100 & 38,64 & 15,37 & 593,97 & 31,13 & 9380 \\
\hline & 150 & 37,96 & 16,17 & 613,50 & 31,37 & 9503 \\
\hline C.V. $(\%)$ & & 6,02 & 6,23 & 8,01 & 8,56 & 10,36 \\
\hline Média Geral & & 38,17 & 15,65 & 596,94 & 31,17 & 8905 \\
\hline
\end{tabular}

(1) $\mathrm{Y}=7672,9+32,532 \mathrm{X}-0,138 \mathrm{X}^{2}, \mathrm{R}^{2}=0,97 * * \mathrm{e} \mathrm{PM}=118 \mathrm{~kg} \mathrm{ha}^{-1}$ de $\mathrm{P}_{2} \mathrm{O}_{5}$. Médias seguidas de mesma letra na coluna não diferem pelo teste de Tukey, a $5 \%$ de probabilidade. ** Significativo a $1 \%$. C = MAP convencional, $\mathrm{P}=$ MAP revestido por polímeros.

Tabela 4. Números de grãos por fileira (NGF), de fileiras por espiga (NFE), de grãos por espiga (NGE), massa de 100 grãos (MCG) e produtividade de grãos (PG) de milho safrinha (em 2011) em função dos tratamentos

\begin{tabular}{|c|c|c|c|c|c|c|}
\hline Tratamentos & & NGF & NFE & NGE & $\begin{array}{c}\text { MCG } \\
(\mathrm{g})\end{array}$ & $\begin{array}{c}\text { PG } \\
\left(\mathrm{kg} \mathrm{ha}^{-1}\right)\end{array}$ \\
\hline \multirow[t]{4}{*}{ Formas de MAP } & C 0052 & $33,90 \mathrm{a}$ & $17,02 \mathrm{a}$ & $578,81 \mathrm{a}$ & $23,29 \mathrm{a}$ & $6846 a$ \\
\hline & P 0041 & 34,29 a & $16,83 \mathrm{a}$ & $577,30 \mathrm{a}$ & $24,00 \mathrm{a}$ & $6914 \mathrm{a}$ \\
\hline & P 0056 & $35,08 \mathrm{a}$ & $16,33 \mathrm{a}$ & $572,90 \mathrm{a}$ & $24,69 \mathrm{a}$ & $7442 \mathrm{a}$ \\
\hline & P 0228 & $34,85 \mathrm{a}$ & 16,79 a & $585,50 \mathrm{a}$ & $24,84 \mathrm{a}$ & $6735 \mathrm{a}$ \\
\hline \multicolumn{2}{|l|}{ D.M.S. $(5 \%)$} & 1,66 & 0,72 & 40,64 & 2,60 & 782 \\
\hline \multirow{4}{*}{$\begin{array}{l}\text { Dose de } \mathrm{P}_{2} \mathrm{O}_{5} \\
\left(\mathrm{~kg} \mathrm{ha}^{-1}\right)\end{array}$} & 0 & 34,00 & 16,83 & 573,39 & 23,66 & 6573 \\
\hline & 50 & 34,42 & 16,96 & 583,32 & 24,21 & 6980 \\
\hline & 100 & 34,12 & 16,83 & 574,28 & 24,88 & 7264 \\
\hline & 150 & 35,58 & 16,42 & 583,53 & 24,04 & 7119 \\
\hline \multicolumn{2}{|l|}{ C.V. (\%) } & 5,09 & 4,47 & 7,44 & 11,40 & 11,87 \\
\hline \multicolumn{2}{|l|}{ Média Geral } & 34,53 & 16,76 & 578,63 & 24,20 & 6984 \\
\hline
\end{tabular}

Médias seguidas de mesma letra na coluna não diferem pelo teste de Tukey, a $5 \%$ de probabilidade. $\mathrm{C}=\mathrm{MAP}$ convencional, $\mathrm{P}=\mathrm{MAP}$ revestido por polímeros. 
as quantidades de microfissuras em sua superfície e o tamanho do grânulo do fertilizante determinam a taxa de liberação de nutrientes ao longo do tempo (Girardi \& Mourão Filho, 2003). Neste trabalho, ressaltam-se, principalmente, as altas temperaturas observadas, assim como a abundância de água, uma vez que os dois cultivos foram irrigados.

$\mathrm{O}$ teor foliar de $\mathrm{P}$ foi influenciado positivamente pelas doses de $\mathrm{P}_{2} \mathrm{O}_{5}$, na segunda safra (Tabela 2), observandose ajuste à função quadrática, com o ponto de máximo teor de $\mathrm{P}$ sendo alcançado com a estimativa de aplicação de $115 \mathrm{~kg} \mathrm{ha}^{-1}$ de $\mathrm{P}_{2} \mathrm{O}_{5}$, independentemente da forma de MAP utilizada. Nos dois cultivos (Tabelas 1 e 2), os teores foliares de $\mathrm{P}$ para as diferentes doses e formas de MAP ficaram dentro da faixa de referência (2,0-4,0 $\mathrm{g} \mathrm{kg}^{-1}$ de P), descrita por Cantarella et al. (1997). Nesse sentido, as doses de fósforo aplicadas na safra (2009/10) e na safrinha (2010) estão sendo suficientes para manter, de forma adequada, o teor desse nutriente nas folhas, não comprometendo, assim, o desenvolvimento da cultura.

Os resultados obtidos para altura de inserção da primeira espiga e altura de planta estão de acordo com os obtidos por Fabrício et al. (2010), em cujo estudo a forma de fornecimento de fósforo (MAP ou MAP revestido por Policote $^{\circledR}$ ) não proporcionou diferenças significativas na altura de plantas e de inserção da espiga (Tabelas 1 e 2). No entanto, houve ajuste das doses de fósforo apenas para altura de planta, sendo observado incremento linear, variando de 2,05 a 2,10 m de altura de planta, no cultivo safrinha (Tabela 2).

A produtividade de grãos de milho na primeira safra foi influenciada positivamente pelas doses de $\mathrm{P}_{2} \mathrm{O}_{5}$ (Tabela 3), ajustando-se à função quadrática, com ponto de máximo sendo obtido com a estimativa de $118 \mathrm{~kg} \mathrm{ha}^{-1} \mathrm{de}$ $\mathrm{P}_{2} \mathrm{O}_{5}$; para o milho safrinha, porém, apesar de existir uma tendência, não houve efeito significativo da adubação fosfatada (Tabela 4). Esse resultado indica que houve efeito residual da adubação fosfatada, realizada na safra 2009/ 2010, o que pode ser explicado pela condução dos experimentos em sistema plantio direto, o qual proporciona aumento do teor de $\mathrm{MO}$ e maior atividade da microbiota do solo (Souza et al., 2010), além de o pH do solo estar corrigido e essas condições interferirem no processo, reduzindo a fixação de $\mathrm{P}$ e aumentando seu efeito residual. Sousa \& Lobato (2003) também constataram efeito residual e apresentaram dados de recuperação de 35 a $62 \%$ do P aplicado, após 13 colheitas de milho, em Latossolo argiloso de Cerrado, utilizando, como fonte, o superfosfato simples, em doses variáveis, aplicadas a lanço, de uma única vez, ou, parceladas, no sulco.

As respostas da cultura do milho à adubação fosfatada geralmente são positivas. Prado et al. (2001) observaram aumento linear da produtividade de grãos, até a dose 135 $\mathrm{kg} \mathrm{ha}^{-1}$ de $\mathrm{P}_{2} \mathrm{O}_{5}$, aplicadas tanto em sulco simples como em sulco duplo, na semeadura. Lucena et al. (2000) constataram incremento da produtividade de grãos de milho, porém até a dose de $197 \mathrm{~kg} \mathrm{ha}^{-1}$ de $\mathrm{P}_{2} \mathrm{O}_{5}$, aplicada no sulco de semeadura. Entretanto, Valderrama et al. (2011) não verificaram efeito de doses de fósforo aplicadas na semeadura, sobre a produtividade de grãos de milho em plantio direto, provavelmente em função do cultivo irrigado, do teor médio de $\mathrm{P}$ (31 $\left.\mathrm{mg} \mathrm{dm}^{-3}\right)$ no solo, de acordo com Raij et al. (1997), e da possível baixa exigência em P do híbrido de milho utilizado.

As formas de MAP revestido não diferiram, significativamente, em eficiência de liberação de P, do MAP convencional, para os teores de $\mathrm{P}$ residual no solo, na avaliação na camada de 0-20 cm (Tabela 5). Nesse sentido, os teores desse elemento no solo são equivalentes, apresentando teor de fósforo no solo tido como médio. Silva

Tabela 5. Teores de fósforo (P) remanescentes no solo, nas profundidades de 0-20 e de 20-40 cm em função dos tratamentos

\begin{tabular}{|c|c|c|c|}
\hline \multirow[t]{2}{*}{ Tratamentos } & & \multicolumn{2}{|c|}{$\begin{array}{c}\text { Teor de } \mathbf{P} \text { (resina) } \\
\qquad\left(\mathrm{mg} \mathrm{dm}^{-3}\right)\end{array}$} \\
\hline & & $0-20 \mathrm{~cm}$ & $20-40 \mathrm{~cm}$ \\
\hline \multirow[t]{4}{*}{ Formas de MAP } & $\mathrm{C} 0052$ & $16,3 \mathrm{a}$ & $6,5 \mathrm{ab}$ \\
\hline & P 0041 & $21,1 \mathrm{a}$ & $5,6 \mathrm{~b}$ \\
\hline & P 0056 & $25,9 \mathrm{a}$ & $11,5 \mathrm{a}$ \\
\hline & Р 0228 & $31,4 \mathrm{a}$ & $6,3 \mathrm{ab}$ \\
\hline \multicolumn{2}{|l|}{ D.M.S. (5\%) } & 17,7 & 5,5 \\
\hline \multirow{4}{*}{$\begin{array}{l}\text { Dose de } \mathrm{P}_{2} \mathrm{O}_{5} \\
\left(\mathrm{~kg} \mathrm{ha}^{-1}\right)\end{array}$} & 0 & $10,5^{(1)}$ & $4,0^{(2)}$ \\
\hline & 50 & 20,4 & 6,4 \\
\hline & 100 & 27,8 & 8,6 \\
\hline & 150 & 36,0 & 10,9 \\
\hline \multicolumn{2}{|l|}{ C.V. $(\%)$} & 21,52 & 16,60 \\
\hline \multicolumn{2}{|l|}{ Média Geral } & 23,6 & 7,5 \\
\hline
\end{tabular}

(1) $\mathrm{Y}=11,08+0,1676 \mathrm{X}, \mathrm{R}^{2}=0,99 * *$. (2) $\mathrm{Y}=4,04+0,0458 \mathrm{X}, \mathrm{R}^{2}=0,99 * *$ Médias seguidas de mesma letra na coluna não diferem pelo teste de Tukey, a $5 \%$ de probabilidade. ** Significativo a $1 \%$. C = MAP convencional, $\mathrm{P}=$ MAP revestido por polímeros. 
et al. (2012) avaliaram a influência da aplicação de diferentes fontes de MAP (revestido e convencional) na cultura do milho, constatando que, independentemente da fonte aplicada, o solo apresentou teor de P remanescente equivalente. Portanto, não compensa, para o agricultor, pagar mais por este tipo de fertilizante considerado moderno, pois as condições edafoclimáticas locais parecem degradar em curto prazo os polímeros que revestem seus grânulos. Isso serve como alerta para a agricultura brasileira, pois parte dos agricultores está adquirindo essa forma de fertilizante, mais cara e com a mesma eficiência do MAP convencional.

Ressalta-se, portanto, que no caso do $\mathrm{P}$, práticas simples, como calagem, uso do plantio direto e a presença de matéria orgânica seriam mais eficazes para reduzir o problema da sua elevada adsorção no solo, não havendo necessidade da utilização de fertilizantes de liberação lenta para esse nutriente, como os MAP revestidos por polímeros, que não mostraram o efeito esperado.

Analisando-se o teor de P na camada de 20 a 40 $\mathrm{cm}$, verifica-se diferença significativa entre as formas P 0056 e P 0041, mas nenhuma das formas revestidas sobressaiu-se à convencional (Tabela 5). No entanto, o teor de $\mathrm{P}$ no solo foi influenciado positivamente e de forma linear pelas doses de $\mathrm{P}_{2} \mathrm{O}_{5}$, na profundidade de 0-20 cm, sendo que as doses de 50,100 e $150 \mathrm{~kg} \mathrm{ha}^{-1} \mathrm{de}$ $\mathrm{P}_{2} \mathrm{O}_{5}$, na semeadura, nos dois cultivos do ano agrícola 2009/2010, proporcionaram teores médios de $\mathrm{P}$ (resina), no solo, de 20,$4 ; 27,8 ; 36,0 \mathrm{mg} \mathrm{dm}^{-3} \mathrm{de}_{2} \mathrm{O}_{5}$, respectivamente. Na profundidade de $20-40 \mathrm{~cm}$, as doses de fósforo aplicadas também influenciaram positivamente e de forma linear o teor de P no solo, variando de 4,0 a $10,9 \mathrm{mg} \mathrm{dm}^{-3}$.

O solo do tratamento que não recebeu a aplicação desse elemento, em quatro cultivos sucessivos (safra 2009/2010, safrinha 2010, safra 2010/2011 e safrinha 2011) apresentou teor baixo de $\mathrm{P}\left(10,5 \mathrm{mg} \mathrm{dm}^{-3}\right)$. Este resultado explica porque as menores produtividades de grãos de milho, na safra 2010/2011 e safrinha 2011, foram obtidas nos tratamentos que não receberam a aplicação de fósforo (Tabelas 3 e 4). Segundo Coelho \& França (2009), para cultura do milho, no que se refere à exportação dos nutrientes nos grãos, o fósforo é quase todo translocado para as sementes (80 a 90\%). De acordo com Coelho et al. (2006), para cada tonelada de grãos produzida pela cultura do milho, são exportados $10 \mathrm{~kg}$ de $\mathrm{P}_{2} \mathrm{O}_{5}$, o que justifica a diminuição deste teor no solo onde o fósforo não foi aplicado, assim como as menores produtividades, nessa condição. Contudo, salienta-se que a redução do teor de $\mathrm{P}$ (11 $\left.\mathrm{mg} \mathrm{dm}^{-3}\right)$ no solo, após quatro cultivos de milho, só não foi maior, porque a palhada dos cultivos anteriores contribuiu para repor parte do P extraído do solo.

\section{CONCLUSÕES}

O teor de fósforo residual no solo, nas profundidades de 0-20 e 20-40 cm, aumenta linearmente até a dose de 150 $\mathrm{kg} \mathrm{ha}^{-1}$ de $\mathrm{P}_{2} \mathrm{O}_{5}$, porém, não há diferença para os fertilizantes utilizados.

As formas de MAP revestidos por polímeros proporcionam o mesmo efeito residual do MAP convencional, para os teores foliares de $\mathrm{P}$ e de clorofila, componentes de produção e produtividade de grãos de milho irrigado, na primeira e segunda safra.

O incremento das doses de fósforo, aplicadas nas culturas anteriores (milho), proporciona efeito residual, pois interfere positivamente no teor de $\mathrm{P}$ foliar e na altura de plantas do milho safrinha e aumenta, até a dose de $118 \mathrm{~kg}$ ha-1 de $\mathrm{P}_{2} \mathrm{O}_{5}$, produtividade de grãos de milho, na primeira safra, independentemente da forma de MAP.

\section{AGRADECIMENTOS}

À Fundação de Amparo à Pesquisa do Estado de São Paulo (FAPESP), pela concessão de bolsa de iniciação científica do primeiro autor e pelo apoio financeiro à pesquisa, Processo: 2010/09348-1.

\section{REFERÊNCIAS}

Araújo FF (2011) Disponibilização de fósforo, correção do solo, teores foliares e rendimento de milho após a incorporação de fosfatos e lodo de curtume natural e compostado. Acta Scientiarum, 33:355-360.

Agrianual (2011) Anuário da agricultura brasileira. São Paulo, FNP Consultoria e Comércio. 482p.

Cantarella H (2007) Nitrogênio. In: Novais RF, Alvarez VVH, Barros NF, Fontes RLF, Cantarutti RB \& Neves JCL (Eds.) Fertilidade do solo. Viçosa, Sociedade Brasileira de Ciência do Solo. p.375-470.

Cantarella H, Raij B van \& Camargo CEO (1997) Cereais. In: Raij B van, Cantarella H, Quaggio JA \& Furlani AMC (Eds.) Recomendações de calagem e adubação para o Estado de São Paulo. Campinas, IAC. p.45-71. (Boletim técnico, 100).

Coelho AM, França GE, Pitta GVE, Alves VMC \& Hermani LC (2006) Nutrição e adubação do milho. Disponível em: <http:// sistemasdeproducao.cnptia.embrapa.br/FontesHTML/Milho/ CultivodoMilho_2ed/feraduba.htm>. Acessado em: 28 de abril de 2012 .

Coelho AM \& França GE (2009) Nutrição e adubação do milho. Disponível em: <http://www.cnpms.embrapa.br/milho/ deficiencia/deficiencia.html>. Acessado em: 28 de abril de 2012.

Conab - Companhia Nacional de Abastecimento (2012) Acompanhamento da safra brasileira - Grãos: safra 2011/2012 - Décimo Primeiro Levantamento. Disponível em: 〈www.conab.gov.br〉. Acessado em: 12 de março de 2012.

Embrapa - Empresa Brasileira de Pesquisa Agropecuária (2006) Sistema brasileiro de classificação de solos. 2a ed. Rio de Janeiro, Embrapa. 306p. 
Fabrício VAF, Renzo GVP, Ivan VAF, Guilherme TMO, Diego CM, Guilherme LA, Roberto R \& Luciano CBPJ (2010) Estado nutricional e produtividade de milho em função de doses e fontes de fósforo. In: $28^{\circ}$ Congresso Nacional de Milho e Sorgo, Goiânia. Anais, Associação Brasileira de Milho e Sorgo. p.1-4.

Ferreira DF (2008) SISVAR: um programa para análises e ensino de estatística. Revista Symposium, 6:36-41.

Figueiredo CC, Barbosa DV, Oliveira SA, Fagioli M \& Sato JH (2012) Adubo fosfatado revestido com polímero e calagem na produção e parâmetros morfológicos de milho. Revista Ciência Agronômica, 43:446-452.

Girardi EA \& Mourão Filho FAA (2003) Emprego de fertilizantes de liberação lenta na formação de pomares de citros. Revista Laranja, 24:507-518.

Guareschi RF, Gazolla PR, Perin A \& Santini JMK (2011) Adubação antecipada na cultura da soja com superfosfato triplo e cloreto de potássio revestidos por polímeros. Ciência e Agrotecnologia, 35:643-648.

Jagadeeswaran R, Murugappan V \& Govindaswamy M (2005) Effect of slow release NPK fertilizer sources on the nutrient use efficiency in turmeric (Curcuma longa L.). World Journal of Agricultural Sciences, 1:65-69.

Jarosiewicz A \& Tomaszewska M (2003) Controlled-release NPK fertilizer encapsulated by polymeric membranes. Journal of Agricultural and Food Chemistry, 51:413-417.

Lucena LFC, Oliveira FAZ, Silva IF \& Andrade AP (2000) Resposta do milho a diferentes dosagens de nitrogênio e fósforo aplicados ao solo. Revista Brasileira de Engenharia Agrícola e Ambiental, 4:334-337.

Machado VJ \& Souza CHE (2012) Disponibilidade de fósforo em solos com diferentes texturas após aplicação de doses crescentes de fosfato monoamônico de liberação lenta. Bioscience Journal, 28:1-7.

Prado RM, Fernandes FM \& Roque CG (2001) Resposta da cultura do milho a modos de aplicação e doses de fósforo, em adubação de manutenção. Revista Brasileira de Ciência do Solo, 25:8390 .
Raij B van, Cantarella H, Quaggio JA \& Furlani AMC (1997) Recomendações de adubação e calagem para o Estado de São Paulo. Campinas, IAC. 285p.

Raij B van, Andrade JC, Cantarella H \& Quaggio JA (2001) Análise química para avaliação da fertilidade de solos tropicais. Campinas, IAC. $285 \mathrm{p}$.

Resende AV, Furini Neto AE, Alves VMC, Muniz JA, Curi N, Faquin V, Kimpara DI, Santos JZL \& Carneiro LF (2006) Fontes e modos de aplicação de fósforo para o milho em solo cultivado da região do Cerrado. Revista Brasileira de Ciência do Solo, 30:453-466.

Silva AA, Silva TS, Vasconcelos ACP \& Lana RMQ (2012) Influência da aplicação de diferentes fontes de MAP revestido com polímeros de liberação gradual na cultura do milho. Bioscience Journal, 28:240-250

Sousa DMG \& Lobato E (2003) Adubação fosfatada em solos da região do Cerrado. Piracicaba, Potafos. 16p. (Informações Agronômicas, 102).

Sousa DMG \& Lobato E (2004) Adubação fosfatada em solos da região do cerrado. In: Yamada T \& Abdalla SRS (Eds.) Fósforo na agricultura brasileira. Piracicaba, Potafos. p.157-200.

Souza RF, Faquin V, Sobrinho RRL \& Oliveira EAB (2010) Influência de esterco bovino e calcário sobre o efeito residual da adubação fosfatada para a Brachiaria brizantha cultivada após o feijoeiro. Revista Brasileira de Ciência do Solo, 34:143-150.

Valderrama M, Buzetti S, Benett CGS, Andreotti M, Arf O \& Sá ME (2009) Fontes e doses de nitrogênio e fósforo em feijoeiro no sistema plantio direto. Pesquisa Agropecuária Tropical, 39:191-196.

Valderrama M, Buzetti S, Benett CGS, Andreotti M \& Teixeira Filho MCM (2011) Fontes e doses de NPK em milho irrigado sob plantio direto. Pesquisa Agropecuária Tropical, 41:254263 . 